\title{
Abstract
}

\section{Mutations of the BRCA1 and BRCA2 Genes in Danish Patients Diagnosed at Young Age with Multi-Centric or Bilateral Breast Cancer}

\author{
J.T. Bergthorsson ${ }^{1}$, K. Winther ${ }^{1}$, K. Fenger ${ }^{1}$, \\ A. Niebuhr ${ }^{1}$, S. Klausen ${ }^{2}, \AA$. Borg ${ }^{3}$, \\ T. Harboe ${ }^{1}$, B. Ejlertsen ${ }^{4}$ and E. Niebuhr ${ }^{1}$ \\ ${ }^{1}$ Department of Medical Genetics, \\ Copenhagen University, Denmark \\ ${ }^{2}$ Department of Pathology, Herlev, Denmark \\ ${ }^{3}$ Department of Oncology, University \\ Hospital, Lund, Sweden \\ ${ }^{4}$ The Finsen Center, Department of \\ Oncology, State University Hospital, \\ Copenhagen, Denmark
}

Germline mutations in the BRCA1 and BRCA2 genes account for about $5 \%$ of the total breast cancer incidence in western populations. In this study we screened a group of 119 Danish breast cancer patients for mutations in both genes using single strand conformation analysis (SSCA) and the protein truncation test (PTT). Our patents were diagnosed at young age $(<45$ years $)$ and had either bilateral $(\mathrm{N}=58)$ or multicentric $(\mathrm{N}=61)$ disease.

The mutation frequency was about equal in the two groups $(11 \%, 12 \%$ respectively). We identified 27 mutation carriers (23\%) and 20 distinct mutations. The ratio of BRCA1 and BRCA2 mutations was similar. Three of the mutations were recurrent in our material, the one most commonly observed (BRCA1: del2954C) was detected in four of the patients. Nine of the mutations are novel, of which six are in BRCA2.

BRCA1 tumours were primarily steroid receptor negative invasive ductal carcinomas and of medullary type. BRCA2 tumours were typically positive for receptors and often of the lobular type.

As the frequency of mutations is higher in our study than other comparable studies where patients are selected on the basis of young age at onset, we conclude that bilaterality and multicentricity are factors associated with BRCA1 and BRCA2 mutation carrier status. 


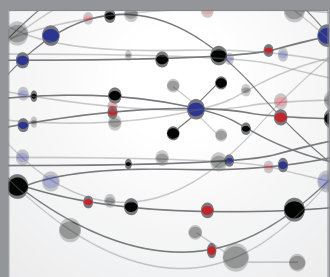

The Scientific World Journal
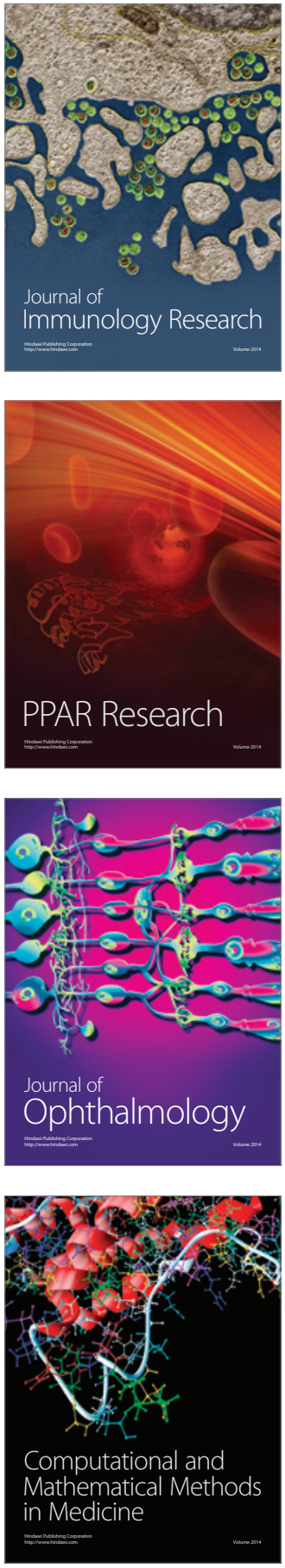

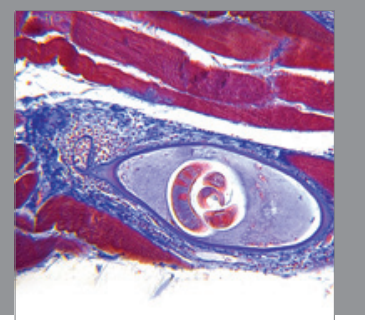

Gastroenterology

Research and Practice
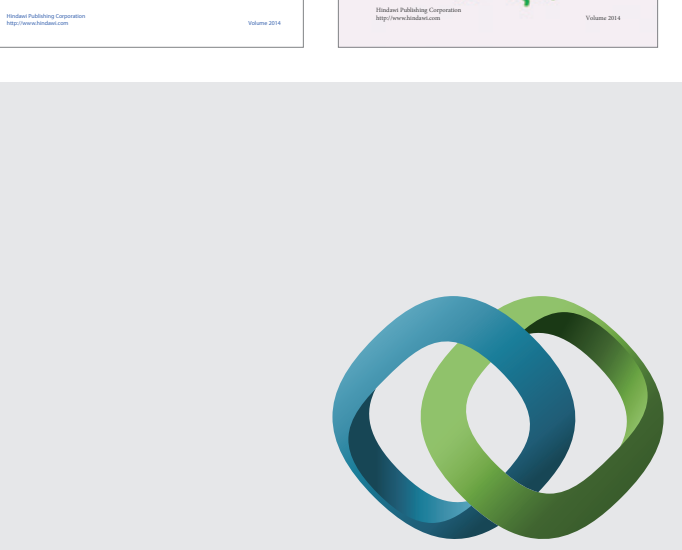

\section{Hindawi}

Submit your manuscripts at

http://www.hindawi.com
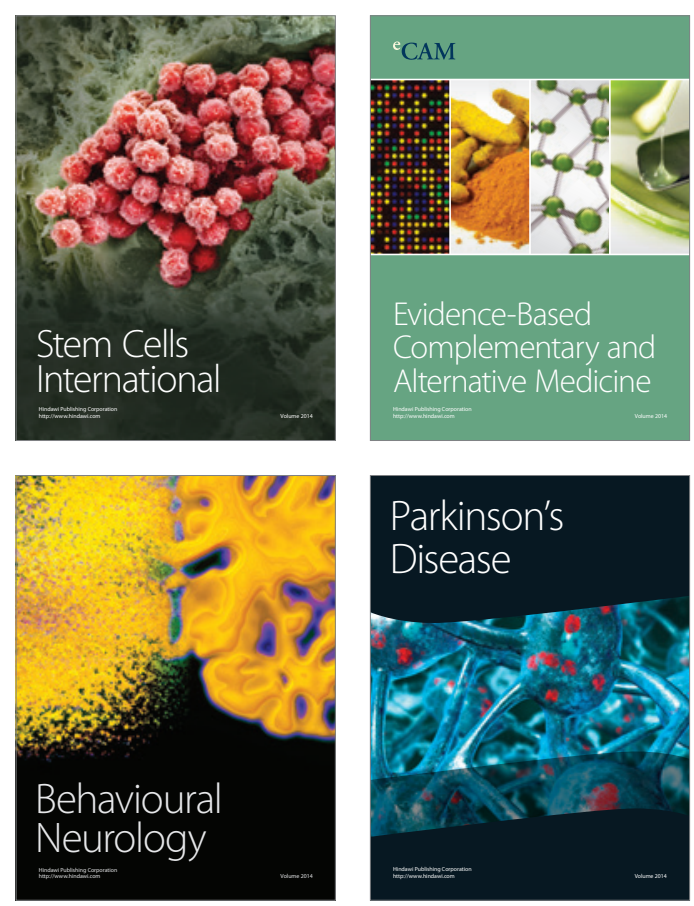

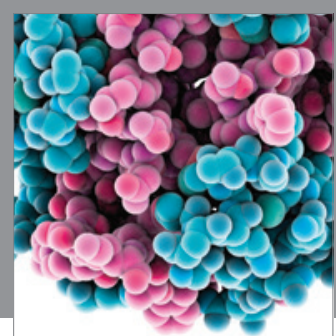

Journal of
Diabetes Research

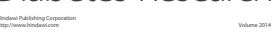

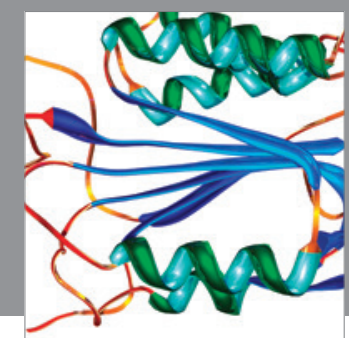

Disease Markers
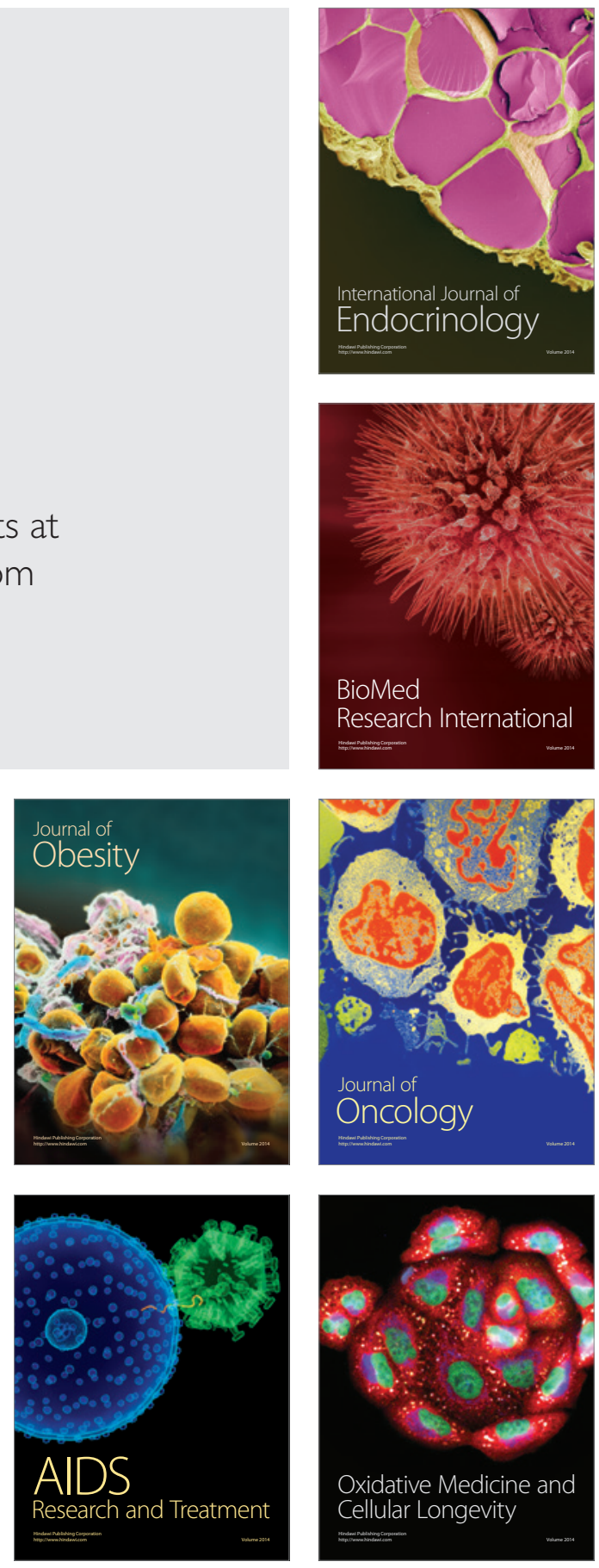